\title{
Effects of Higher Percentage of Stone Dust Used as a Fine Aggregate in Concrete and Variation of Strength due to the Variation of Cement Content and W/C Ratio
}

\author{
Bikram Paul $^{1}$, Kushal Ghosh ${ }^{2}$ and Partha Ghosh ${ }^{3}$ \\ ${ }^{1} \mathrm{PG}$ Student, ${ }^{2} \mathrm{PhD}$ Student, ${ }^{3}$ Associate Professor \\ Department of Construction Engineering, Jadavpur University, Kolkata, West Bengal, India \\ E-Mail: bikram.bubai@gmail.com, kushalghosh100@gmail.com, parthghosh78@yahoo.co.in
}

\begin{abstract}
Sustainability and Unavailability play an important role while we choose material for manufacturing of concrete. Nowadays, both Central and State Govt. have taken legal action on the extraction of sand from the river bed due to the bad impacts on the river like changes the shape, slope of the bed and also in the channel morphology. Due to the implementation of this type of law, legal sand quarries did not able to make balance with the rapid growth of the construction industry. That's why, to make profit and supply extra needs of sand to the concrete industry "Sand Mafias" involved into the illegal trades of the sand. To counteract these sorts of socioeconomic problems, we have to go for an alternative fine aggregate. Though it may not be possible to replace fully, we have to concentrate on the sand being replaced by the high percentage of alternative fine aggregate. Stone dust is a byproduct from rock crusher and it can be recycled by using it in the concrete and maintained the sustainability. As stone dust has acceptable properties of fine aggregate sand with regard to shape and texture, it can be thought of as an alternate fine aggregate but research is needed on the extent of sand replacement by stone dust. The present study is done keeping in mind the use of stone dust as high as possible. That's why two Design Mix have been designed M20 and M25. For M20 grade of concrete sand has been replaced by stone dust $25 \%$, $30 \%$ and $35 \%$ by volume and the basic strength properties of concrete have been investigated for the above replacements like compressive strength, flexural strength, split tensile strength etc. In case of M25 grade of concrete $30 \%, 40 \%$ and $50 \%$ replacement of sand have been done and variation cement content and water-cement ratio has been done by comparing the target mean strength of M25 grade of concrete. Keywords: Stone Dust, Fine Aggregate, Concrete, Cement, W/C Ratio
\end{abstract}

\section{INTRODUCTION}

Many years ago, industrialization had been started from the banks of the river but these rivers get polluted by the industry waste, not only the river but the whole environment gets serious alarm. That's why, the research is needed to start on the by-products from various industries which are being used as a constituent in concrete for many years. Nowadays, the efforts have been made to use industry byproducts such as fly ash, GGBS, silica fume, waste foundry sand, glass, etc., in concrete manufacturing and civil applications. Depending on the physical and chemical properties these by-products are mainly limited to use partially in concrete as a replacement of any major ingredients. These by-products have certain environmental hazards and also pose a disposal problem. Concrete is the most widely used construction material in the world and it consists of coarse aggregate, sand and binder as cement. Now the growth of Construction industry indirectly plays a significant role in the development of our infrastructure. This results in huge demand of construction materials. All materials used in concrete are found in form of natural resources.

On the other hand, rapid industrialization has produced waste materials in our society and majority of the waste do not find any effective use and cause a serious disposal problem that leads to health and environmental hazards. These problems can be solved by reusing the industrial waste as aggregate or sometimes as a replacement of cement (if the chemical and physical properties permit to do so). It has been observed that some of these wastes have high potential and can be used as a replacement of the natural resources in construction industry. Different industries have produced different waste products and many of the waste products can be used very effectively in our concrete industry without compromising on strength and durability. Both Sustainability and Unavailability play an important role while we choose material for manufacturing of concrete. Nowadays, both the Central and State Govt. have taken legal action on the extraction of sand from the river bed due to the bad impacts on the river like changes the shape, slope of the bed and also in the channel morphology.

Due to the implementation of this type of law, legal sand quarries are not able to make balance with the rapid growth of the construction industry. That's why, to make profit and supply of extra needs of sand to the concrete industry "Sand Mafias" are involved into the illegal trades of the sand. To counteract these sorts of socio-economic problems, we have to go for an alternative fine aggregate. Though it may not be possible to replace fully, we have to concentrate on the sand being replaced by the high percentage of alternative fine aggregate. Stone dust is a by-product from rock crusher and it can be recycled by using it in the concrete to maintain the sustainability. As stone dust has acceptable properties of 
fine aggregate sand with regard to shape and texture, it can be thought of as an alternate fine aggregate but research is needed on the extent of sand replacement by stone dust.

Omar M. Omar et al., (2012) [1] suggested that the use of limestone dust enhanced the workability of concrete and other mechanical properties (compressive strength, flexural strength, permeability etc.) as well. They replaced sand by $25 \%, 50 \%$ and $75 \%$ both for two mixes and 5\%, 10\%, $15 \%$ of marble powder used as an additive to the cement. Irregular and disorganised shape of LSW particles increased the bond strength that will give advantage to flexural and tensile strength. Another author M. Bederina et al., (2013) [2] showed that increased in the Lime stone crushed sand in the mix leads to increase in flow time of the mix due to the angular shape and higher water adsorption of crushed sand. This higher water absorption by the dust leads to the reduction of availability of water in the mix that helps in reduction of pores in the concrete and finally enhanced the mechanical properties of concrete.

S.N. Raman et al., (2011) [3] showed that granite quarry dust can be utilized with rice husk as a replacement of sand in concrete. They confirmed that higher percentage replacement of sand by quarry dust may have some negative effects but it can be easily compensated by using Rice husk ash as replacement of cement. They also suggested that UPV test represents porosity and density of hardened concrete, quarry dust with RHA behaved better than that of the normal concrete. Sreekrishnaperumal Thanga Ramesh et al., (2013) [4] showed that the furnace and welding slags have been utilized in the work by using it in the building materials as addition to concrete. WS and FS concretes showed better performance towards compressive strength. Celik and Marar (1996) [5] investigated the properties of hardened concrete and mixing stone dust as a partial replacement of sand. They concluded that partial replacement up to $10 \%$ leads to increase in the compressive strength and flexural strength. Strength increment for $10 \%$ replacement is due to the fines filled the voids results in good compact concrete.

\section{RESEARCH SIGNIFICANCE}

The main objective of the research is to find out the higher percentages of stone dust upto which the replacement can be done and at the same time comparative study have been done between the properties of traditional concrete and sustainable concrete. The effects are observed on the compressive strength when cement content and $\mathrm{W} / \mathrm{C}$ ratio have been varied.

\section{EXPERIMENTAL PROGRAM}

\section{A. Materials Used}

\section{Cement}

Portland Pozzolana cement (Fly Ash Based) - under the
Industrial name (Ultratech) conforming to Indian standard IS: 1489 -1991 Part-I was used in whole study.

\section{Coarse Aggregate}

The broken stone is generally used as a coarse aggregate. The nature of work decides the maximum size of the coarse aggregate. Locally available coarse aggregate of maximum size of $20 \mathrm{~mm}$ was used in the present work.

\section{Fine Aggregate}

The material which passes through $4.75 \mathrm{~mm}$ sieve is termed as fine aggregates. The sand used for the experimental works is locally procured and conformed to grading zone III.

\section{Stone Dust}

The Stone Dust used for the experimental works is collected from Nalhati, West Bengal and conformed to grading zone II. Here sieving of stone dust was done using $2.36 \mathrm{~mm}, 1.18$ mm, 600-micron, 300-micron and 150-micron size.

\section{Water}

Water is an important ingredient of concrete as it actively participates in the chemical reaction with cement. Since it helps to form the strength giving C-S-H gel, the quantity and quality of water is required to be looked into very carefully. Potable water is generally considered satisfactory. In the present investigation, tap water is used for both mixing and curing purposes.

\section{Super Plasticizer}

Sikament 2004 NS brand complies with IS: 9103 (1999) and ASTM-C-494 as a high range water reducing admixture. Sikament is a unique combination of the latest generation superplasticisers, based on a Modified Napthalene Formaldehyde Sulphonate. It is supplied as dark brown liquid instantly dispersible in water and specially formulated to give high water reduction. At the start of the mixing process an electrostatic dispersion occurs but the cement particle's capacity to separate and disperse. This mechanism considerably reduces the water demand in concrete. Sikament 2004 NS combines the properties of water reduction and workability retention.

\section{B. Concrete Mix Proportion}

Two Design Mix have been designed M20 and M25. For M20 grade of concrete sand has been replaced by stone dust $25 \%, 30 \%$ and $35 \%$ by volume. In case of M25 grade of concrete $30 \%$, 40\% and 50\% replacement of sand have been done and variation cement content and water-cement ratio has been done by comparing the target mean strength of M25 grade of concrete. 
TABLE I DESIGN MIX PROPORTIONS

\begin{tabular}{|l|c|c|}
\hline \multicolumn{1}{|c|}{ Description } & Mix-1 (M20) & Mix-2 (M25) \\
\hline Cement & $360 \mathrm{Kg} / \mathrm{m} 3$ & $400 \mathrm{Kg} / \mathrm{m} 3$ \\
\hline Sand & $662 \mathrm{Kg} / \mathrm{m} 3$ & $631 \mathrm{Kg} / \mathrm{m} 3$ \\
\hline $\begin{array}{l}\text { Coarse Aggregate } \\
\text { 20mm }\end{array}$ & $751 \mathrm{Kg} / \mathrm{m} 3$ & $748 \mathrm{Kg} / \mathrm{m} 3$ \\
\hline $\begin{array}{l}\text { Fine Aggregate } \\
10 \mathrm{~mm}\end{array}$ & $500 \mathrm{Kg} / \mathrm{m} 3$ & $498 \mathrm{Kg} / \mathrm{m} 3$ \\
\hline Water & $180 \mathrm{~L}$ & $180 \mathrm{~L}$ \\
\hline Admixture & $\begin{array}{c}0.8 \% \text { by Weight } \\
\text { of Cement }\end{array}$ & $\begin{array}{c}0.8 \% \text { by Weight } \\
\text { of Cement }\end{array}$ \\
\hline
\end{tabular}

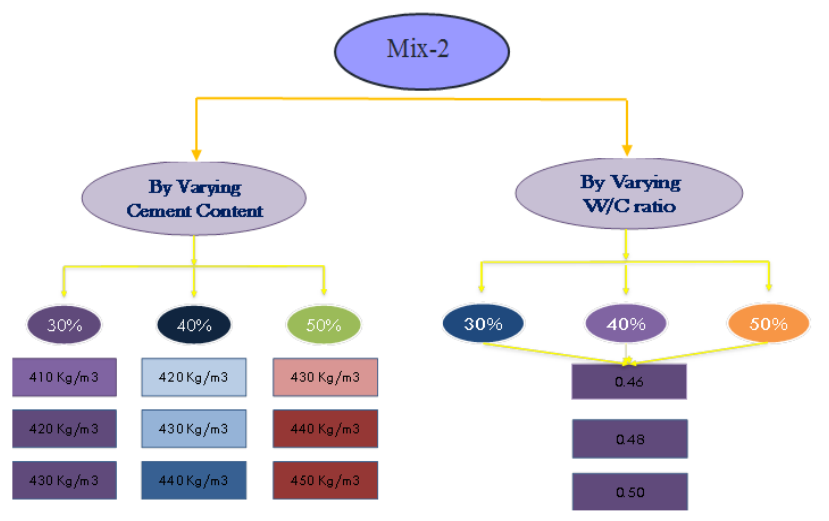

Fig. 1 Flow Charts for Experimental Programme for Mix2

\section{Casting of Specimen}

150mm x 150mm x 150 mm Cube samples were casted for compressive test and flexural Tests were conducted on 150mm x 150mm x 700mm Beam samples. Split Tensile Tests also carried out on cylinder of $150 \mathrm{~mm}$ diameter samples.

\section{RESULT AND DISCUSSION}

\section{A. Compressive Strength}

The mechanical interlocking capacity between the fine aggregate particles and the matrix phase has improved the mechanical performance of the transition zone which ultimately has increased the compressive strength [1]. We can easily conclude from Tables and graphs that small pores or voids are being filled by fines of stone dust and thus increasing compressive strength [5]. We found 25\% is the optimum replacement level for stone dust for all Mix proportions but for Mix 2 up to 30\% level of replacement satisfied the target strength criteria for the respective mix (i.e., 29.19 $\mathrm{MPa}$, and 43.78 $\mathrm{MPa}$ for Mix2) which was confirmed by MD. Nuruzzaman et al., [6] and Lohani T. K et al., [7]. It is important to remember before mixing of finer grading dust that very fines dust should be removed by sieving (150u sieve) and then only it can be replaced beyond $10 \%$. Beyond $25 \%$ the compressive strength decreases which can be attributed to the stiffness of the fresh mix which leads to improper placing and compaction.

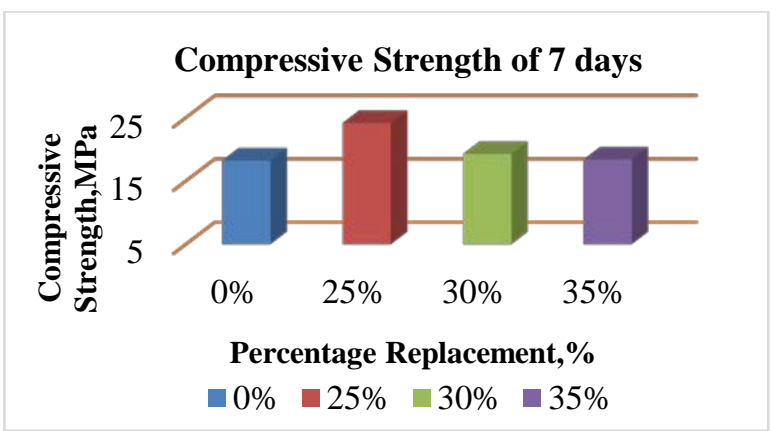

Fig. 2 Compressive Strength of 7 days

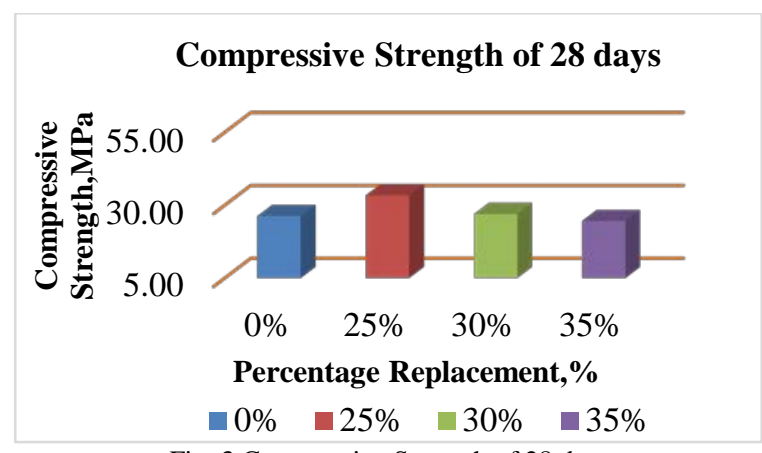

Fig. 3 Compressive Strength of 28 days

\section{B. Flexural Strength}

It can be seen that for Mix 1 at the replacement level 30\% flexural strength decreased than that of normal concrete. Variation in shape and rough texture may improve the bond strength and results in increase of flexural strength that also confirmed by the other authors [1] \& [4]. Results from all the mixes are comparable with each other and we can say that up to $25 \%$ replacement of sand can be done without having an adverse effect on the flexural strength.

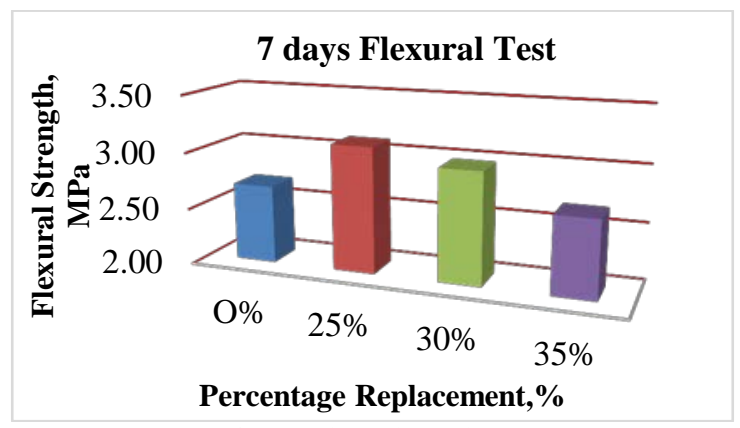

Fig. 4.7 days Flexural Test

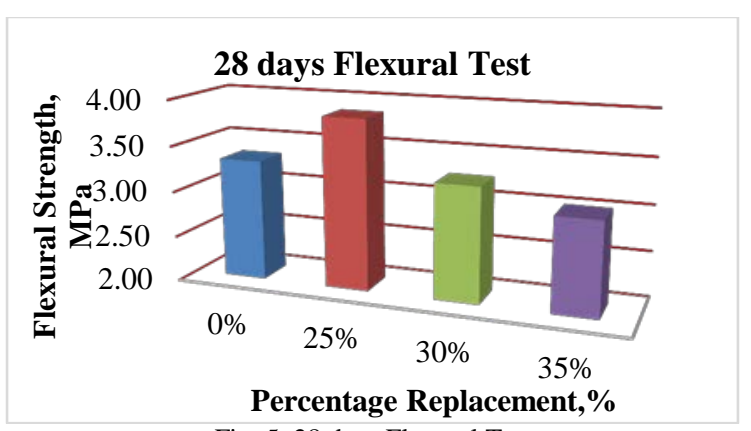

Fig. 5. 28 days Flexural Test 


\section{Split Tensile Strength}

It can be observed that in Mix 3 the split tensile strengths increased for the specimens up to $25 \%$ and at $30 \%$ replacement and this value changes to lower side than that of Normal Concrete of Mix 3. On the other hand, both for 7 days and 28 days split tensile value increased for 35\% replacement though split tension decreased for 30\% replacement. Similar reason can be given for the increment of split tensile strength as that of flexural strength.

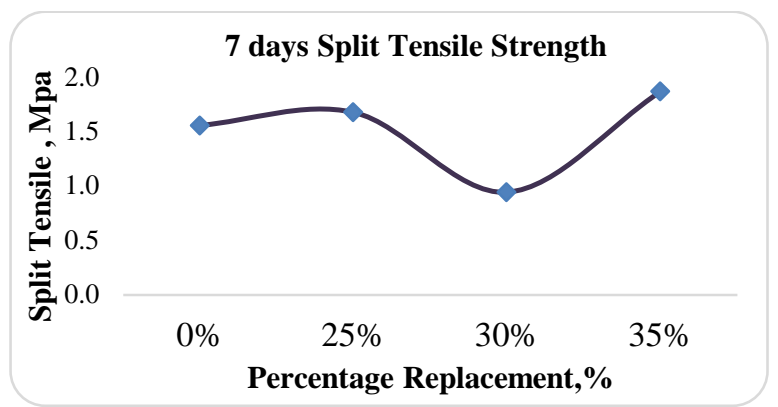

Fig. 6.7 days Split Tensile Strength

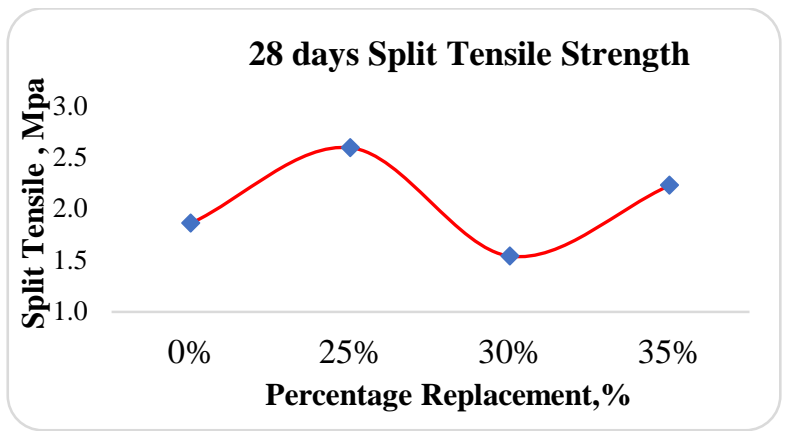

Fig. 7. 28 days Split Tensile Strength

\section{Study of M25 grade of Concrete}

\section{By varying Cement Content}

We have noticed during the study of mechanical properties that compressive strength for mixes containing stone dust beyond 30\% often reduced and could not satisfy the target mean strength of the corresponding mix. Thus, an experimental program was designed where cement content was increased by $10 \mathrm{Kg} / \mathrm{m}^{3}$ from the original mix proportion of Mix 2. Here results are given for 30\%, $40 \%$ and 50\% stone dust replacement. For 30\% replacement, we increased cement content from 410 to $430 \mathrm{Kg} / \mathrm{m}^{3}$ but compressive strength results were not satisfied to the target mean strength of Mix1. Thus, for 30\% replacement we have to increase cement content slight more. For $40 \%$ replacement (Cement Content- 420 to $440 \mathrm{Kg} / \mathrm{m}^{3}$ ) same can be concluded as that of $30 \%$ replacement but compressive strength is satisfied for $50 \%$ replacement (Cement Content430 to $450 \mathrm{Kg} / \mathrm{m}^{3}$ ) with cement content $450 \mathrm{Kg} / \mathrm{m}^{3}$ for the target mean strength of Mix2. With increase in the cement content strength increases for all cases but it is noticed that for $430 \mathrm{~kg}$ cement content and $40 \%$ replacement strength decreases both for 7 days and 28 days. As the dust content in the mix increases with increment of percentage of stone dust compressive strength decreased because of the unavailability of cement particles for dust which are not able to form a paste to provide compressive strength.

\section{By varying Water- Cement Ratio}

It was seen in the mixes that beyond $30 \%$ replacement of stone dust workability decreased and hence, we decided to study the compressive strength by increasing the w/c ratio for each mix. We increase the w/c ratio from 0.46 to 0.50 . All results are showed in the graphical representation in Fig. 10 and Fig. 11. With increase in w/c ratio compressive strength decreases for all the replacement. In the Fig. 12 to Fig. 17 same results have been shown in a different manner. Here for each mix cement content and water cement ratio in different $\mathrm{y}$-axis with compressive strength in $\mathrm{x}$-axis.

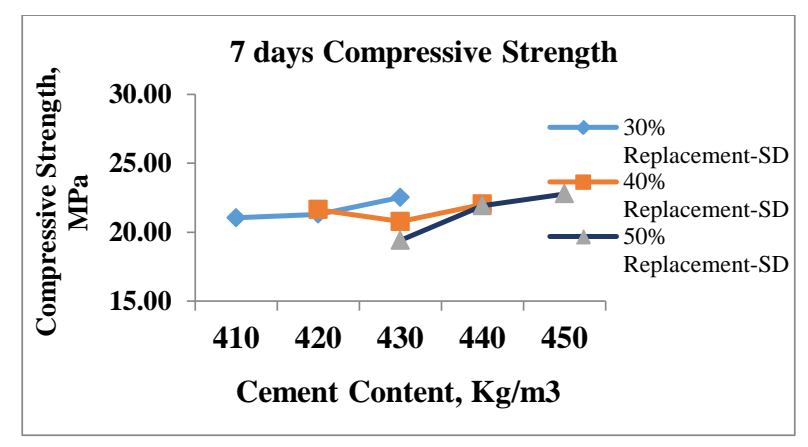

Fig. 8 Cement Content vs. 7 Days Compressive Strength

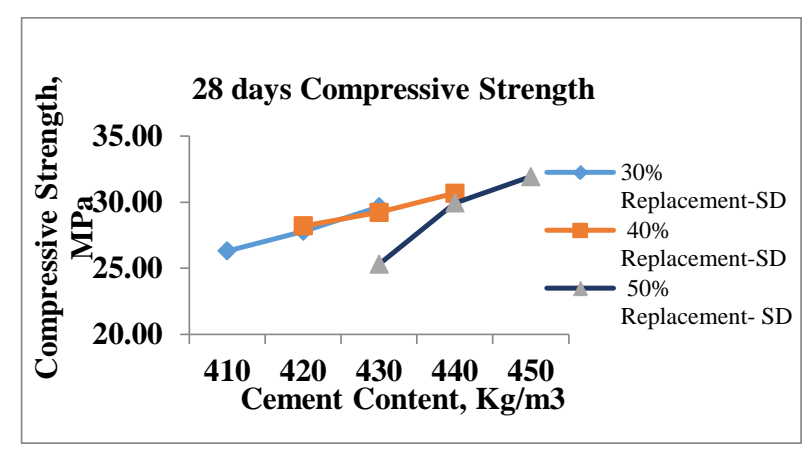

Fig. 9 Cement Content vs. 28 Days Compressive Strength

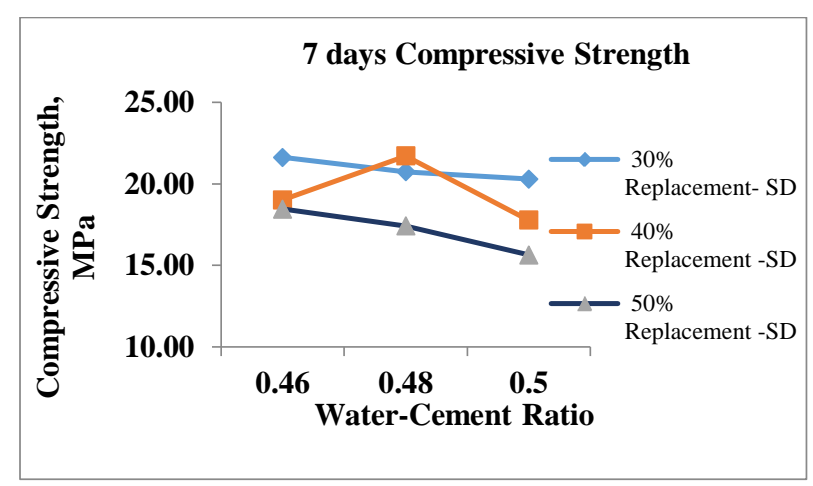

Fig. 10 W/C Ratio vs. 7 Days Compressive Strength 


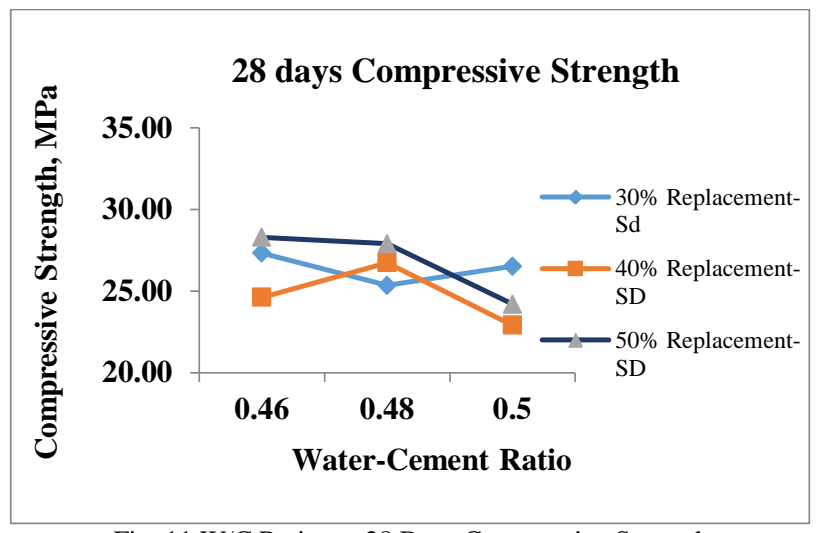

Fig. 11 W/C Ratio vs. 28 Days Compressive Strength

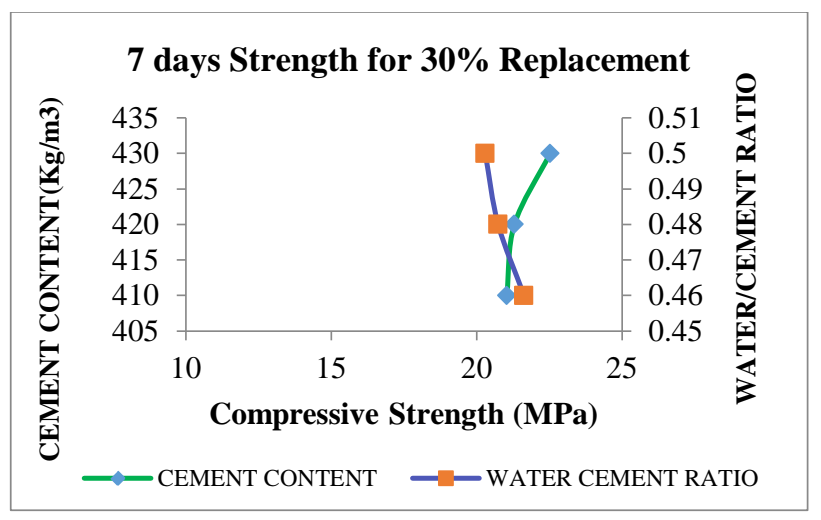

Fig. 12 Compressive Strength vs. 7 days Strength 30\% for Replacement

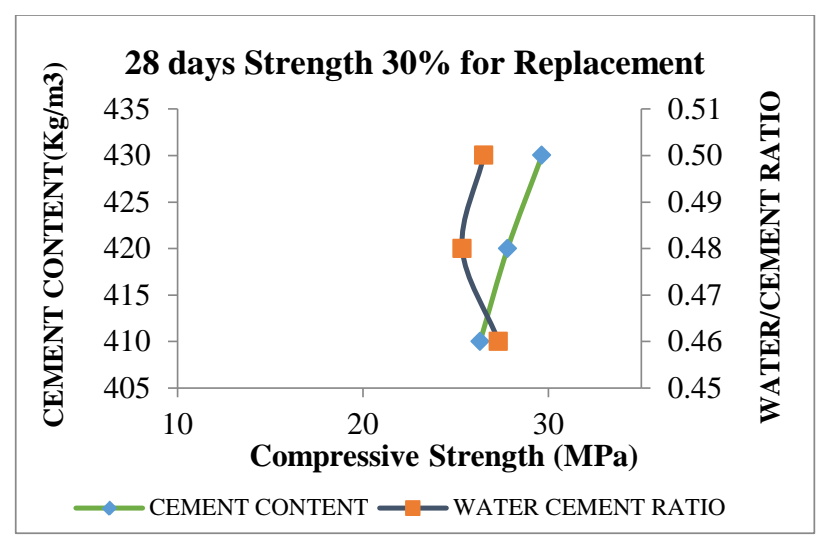

Fig. 13 Compressive Strength vs. 28 days Strength 30\% for Replacement

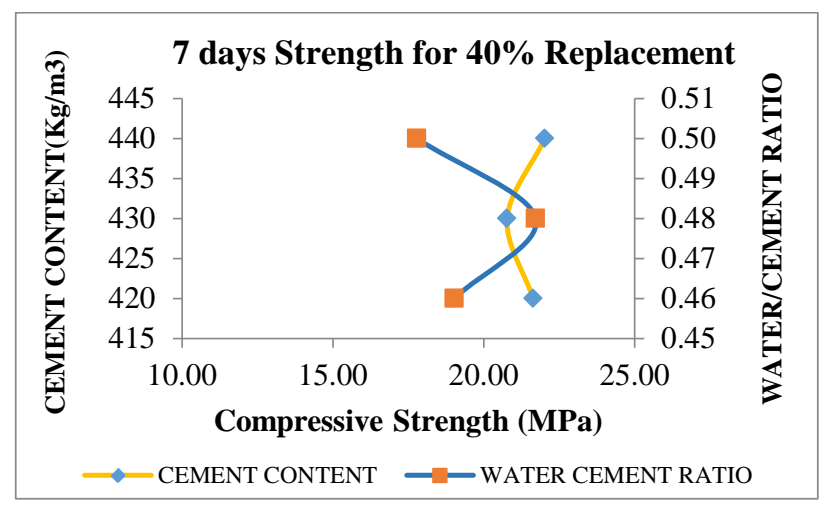

Fig. 14 Compressive Strength vs.7 days Strength 40\% for Replacement

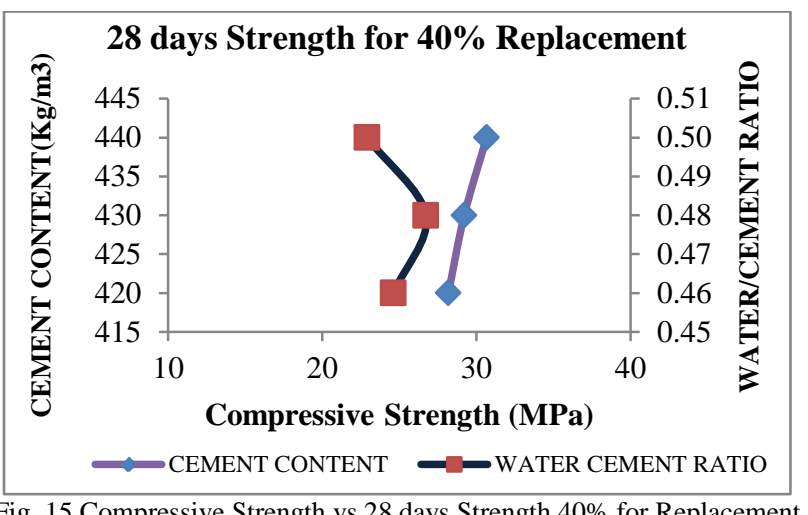

Fig. 15 Compressive Strength vs. 28 days Strength $40 \%$ for Replacement

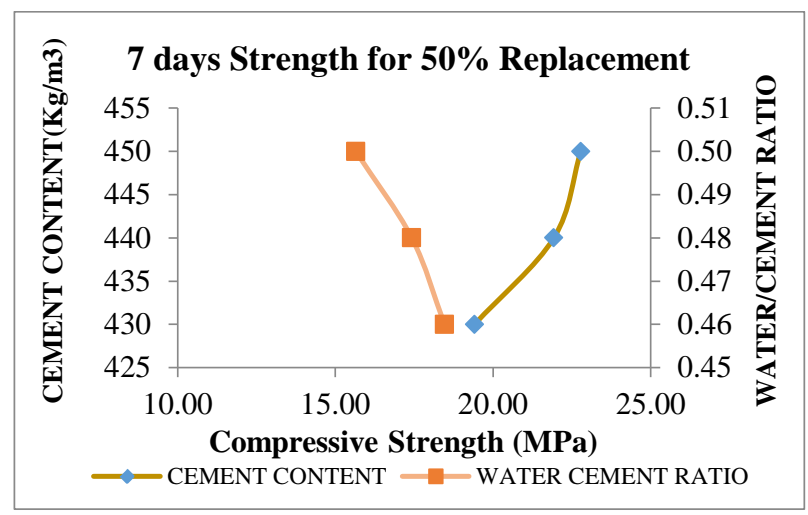

Fig. 16 Compressive Strength vs.7 days Strength 50\% for Replacement

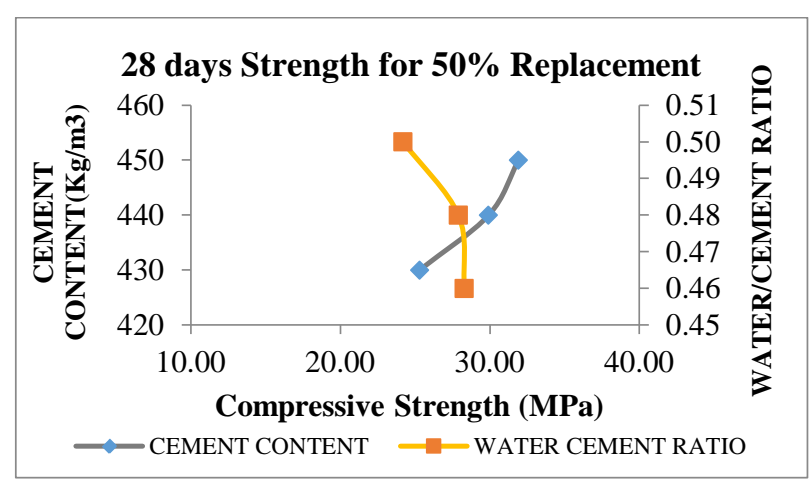

Fig. 17 Compressive Strength vs.28 days Strength 50\% for Replacement

\section{CONCLUSION}

1. Sieving and washing (if possible) should be done for stone dust collected from the quarries. Here we used stone dust particle size between $2.36 \mathrm{~mm}$ and 150 microns.

2. For all mixes compressive strength results showed that $25 \%$ was the optimum percentage to mix with concrete. But we can replace stone dust upto 30\% in mixes with relatively higher cement content.

3. With increasing cement content with percentage increase in replacement level showed increase in compressive strength. For $50 \%$ replacement of sand $450 \mathrm{Kg} / \mathrm{m}^{3}$ cement content was needed to achieve the target mean strength for M25 (Mix 2) grade of concrete. Increasing the water cement ratio did not yield positive results. 


\section{REFERENCES}

[1] Omar and M. Omar, "Influence of limestone waste as partial replacement material for sand and marble powder in concrete properties”, HBRC Journal, Vol. 8, No. 3, pp. 193-203, 2012.

[2] M. Bederina, "Effect of partial and total replacement of siliceous river sand with limestone crushed sand on the durability of mortars exposed to chemical solutions”, Construction and Building Materials, Vol. 47 (2013): 146-158.

[3] Raman, Sudharshan Naidu, "High-strength rice husk ash concrete incorporating quarry dust as a partial substitute for sand”, Construction and Building Materials, Vol. 25, No. 7, pp. 3123-3130, 2011.

[4] Ramesh, Sreekrishnaperumal Thanga, "Use of furnace slag and welding slag as replacement for sand in concrete”, International Journal of Energy and Environmental Engineering, Vol. 4, No. 1, pp. 3, 2013.

[5] Celik, Tahir, and Khaled Marar. "Effects of crushed stone dust on some properties of concrete", Cement and Concrete Research, Vol. 26, No. 7, pp. 1121-1130, 1996.
[6] Nuruzzaman, Md, Md Saiful Islam and M. Salauddin. "Strength aspect of concrete using stone dust as a partial replacement of sand".

[7] T. K. Lohani, "Optimum utilization of Quarry dust as partial replacement of sand in concrete”, Int. J. Appl. Sci. Eng. Res, Vol. 1, No. 2, pp. 391-404, 2012.

[8] R. Ilangovana, N. Mahendrana and K. Nagamanib. "Strength and durability properties of concrete containing quarry rock dust as fine aggregate”, ARPN Journal of Engineering and Applied Sciences, Vol. 3, No. 5, pp. 20-26, 2008.

[9] A. M. Neville - Properties of concrete, ISBN: 978-0-273-75580-7, 2011.

[10] IS 10262:2009, Indian Standard, Concrete Mix Proportioning Guidelines (Fifth Revision).

[11] SP 23:1982, Handbook on Concrete Mixes (Based on Indian Standard), ISBN: 81-7061-012-5.

[12] IS 456:2000, Indian Standard, Plain and Reinforced Concrete - Code of Practice (Fourth Revision). 